\title{
Political Empowerment of Women for Sustainable Development in Ethiopia
}

\author{
Meskerem Legesse Bekele \\ Addis Ababa University, College of Business and Economics, Department of Public Administration and \\ Development Management, Ethiopia
}

\begin{abstract}
The purpose of this study is to examine the different factors affecting women's political empowerment and to find out the contribution of women empowerment through politically to bring sustainable development in Ethiopia. In order to gather relevant data Secondary data were used as a main source of data. The secondary data includes; statistical report, magazines, internal publications, journals and books. The results of the study shows that there is a significant relationship between women's political empowerment and socio-economic variables, social class positions, mass media, political participation experience and political efficacy. All these have a greater impact on women's political empowerment in attaining sustainable development. The study recommended that creating a well-established and structured organizations aimed at facilitating women's empowerment in politics is possible to strengthen the work of government to make it more effective by abolishing the dominance of few powerful rich political elites and by attempting inclusion of women in politics for sustainable development.
\end{abstract}

Keywords: Women Empowerment, Women's Political Empowerment, Sustainable Development

DOI: $10.7176 / \mathrm{JCSD} / 46-01$

Publication date:March $31^{\text {st }} 2019$

\section{Introduction}

Empowerment is demonstrated by the quality of people's participation in the decisions and processes affecting their lives. In theory, empowerment and participation should be different sides of the same coin. In practice, much of what passes for popular participation in development and relief work is not in any way empowering to the poorest and most disadvantaged people in society (Oxfam 1995 as cited by Oxaal \& Baden 2004).

It is a multidimensional concept, which purports to measure a woman's ability to control resources, her ability to choose and control different outcomes, and above all enhance her self-esteem. It can be examined based on different indicators. Until recently, variables such as education and employment were commonly used to capture empowerment and other related concepts such as women's autonomy and status. While those proxy measures are important and are ideally associated with empowerment, they may not capture all aspects of the multidimensional concept of empowerment (Joshi, 1999).

Many United Nations (UN) conferences have advocated that women's empowerment in politics is central to sustainable development. The Copenhagen Declaration of the World Summit on Social Development (WSSD) is a case in point. WSSD called for the recognition that empowering people, particularly women, to strengthen their own capacities is a main objective of development, and that empowerment requires the full participation of people in the formulation, implementation and evaluation of decisions determining the functioning and wellbeing of societies (Baden and Oxaal, 2004).

Ethiopia has been taking policy measures towards empowering women in sustainable development and poverty reduction endeavors. Gender equality and women's empowerment is one of the priority goals towards which many least developed countries like Ethiopia are working for in poverty reduction and sustainable development efforts. In other words, women's empowerment and gender equality is recognized as one of the building blocks in combating poverty and achieving sustainable improvement of livelihoods of a community (United Nations, 2002). Sustainable Development is relatively a new concept that is being considered in many parts of the World including Ethiopia. Sustainable Development encompasses economic, social, cultural, security and participatory in decision making processes. A national women policy has been formulated to encourage the integration of gender issues in the overall development issues of the country and empower women and strengthen their participation in decision-making processes (Medhin Zewdu, 2002).

\section{Justification of the Paper}

Political empowerment of women is becoming an important issue of concern for sustainable development for all over the world. Women empowerment is a powerful instrument for national transformation and sustained economic growth. In addition to these Women's political empowerment helps to ensure gender equality and the wellbeing of nations. When women become politically empowered and get their own share for representation definitely they contributes to the development of a country. But, it is not well recognized in most developing countries including Ethiopia, traditional management techniques play immense ingredient that influence working 
cultures almost in all sectors.

The Political empowerment of women in Ethiopia has been bewildered in a number of problems and challenges over the past years. Many scholars have raised different issues that might have attributes to the root problems in the Ethiopian Politics.

Political empowerment of women is a component of social behavior, because it is one of the major pillars and indicators of political development and it is also closely related to the legitimacy of political systems, and largely reflects the type of political system each community has. The rationale behind this study is to show case the historical back ground of women political empowerment in Ethiopia, discuss on the theoretical background, present overview of the current political empowerment of women including the major factors and problems faced to come to a reasonable conclusion up on which recommendations are made.

Accordingly, this study is meant to address the following questions through the literature and critical analysis:

1. Why do we need the participation of women in political leadership in Ethiopia?

2. What are the factors hindering women's political participation in Ethiopia?

3. Is there enabling environment for women to participate in politics and development?

4. What are the main strategies for women's political participation to sustain development?

\section{Objective of the study}

\subsection{General Objective}

The general objective of the study is to critically examine the Political Empowerment of Women for Sustainable Development in Ethiopia

\subsection{Specific Objective}

The study has also the following specific objectives:

1. To identify the rationale behind the participation of women in political leadership of Ethiopia

2. To find out the challenges and major factors hindering women's political participation in Ethiopia

3. To critically examine enabling environment for women to participate in politics and sustainable development

4. To analyze whether the strategies promoting women's political participation is positively contributed towards sustain development

\section{Methodology of the Paper}

The paper is descriptive type of study which contains qualitative type of data. Secondary data is used as a main source of data; Statistical report, magazines, internal publications, journals and books are used to assess theoretical and practical aspect of women empowerment in politics to promote sustainable development in Ethiopia. Finally descriptive analysis is made by considering both theoretical and empirical literature for having critical analysis and extensive study on political empowerment of women in attaining sustainable development in Ethiopia.

\section{Result and Discussion}

\subsection{Critical Analysis of women political empowerment in Ethiopia}

\subsubsection{Indicators of Political Empowerment}

* Percentage of seats held by women in local councils/ decision-making bodies;

* Percentage of women in decision-making positions in local government;

* Percentage of women in the local civil service;

$\neq$ Percentage of women/men registered as voters/ percentage of eligible women/men who vote;

* Percentage of women in senior/junior decision-making positions within unions;

* Percentage of union members who are women/men;

* Number of women who participate in public progress and political campaigning as compared to the number of men (Oxaal \& Baden, 2004).

\subsubsection{Factors Hindering women's political participation in Ethiopia}

Women at every socio-political level find themselves underrepresented in parliament and far removed from decision-making levels. The factors that hamper or facilitate women's political participation vary with level of socio-economic development, geography, culture, and the type of political system. Women themselves are not a homogeneous group; there are major differences between them, based on class, race, ethnicity, cultural background and education. The structural and functional constraints faced by women are shaped by social and political relations in a society. The common pattern of women's political exclusion stem from (a) social and political discourses (b) political structures and institutions (c) the socio-cultural and functional constraints that put limits on women's individual and collective agency. 


\subsubsection{Socio-Cultural Factors}

The subordinate status of women vis-à-vis men is a universal phenomenon, though with a difference in the nature and extent of subordination across countries. Gender role ideology does not only create duality of femininity and masculinity, it also places them in hierarchal fashion in which female sex is generally valued less than male sex because of their socially ascribed roles in reproductive sphere. The gender status quo is maintained through low resource allocation to women's human development by the state, society and the family. This is reflected in the social indicators which reflect varying degrees of gender disparities in education, health, employment, ownership of productive resources and politics in all countries. Additionally gender is mediated through class, caste and ethnicity that structure access to resources and opportunities. The socio-cultural dependence of women is one of the key detrimental factors to their political participation in public political domain. Women also find it hard to participate in politics due to limited time available to them because of their dual roles in the productive and reproductive spheres. With their primary roles as mothers and wives and competing domestic responsibilities and care work, they are left with little time to participate in politics. In some of the countries, particularly in South Asia, women also face cultural constraints on their mobility. The mechanisms of sex segregation and purdah are used to restrict their mobility. Politics requires women's exposure to interact with male and female constituents and address public meeting.

\subsubsection{Political Factors}

The nature of politics is an important factor for the inclusion or exclusion of women in politics. Vicky Randall defines politics as an "articulation, or working out of relationships within an already given power structure", which is in contrast with the traditional view of politics that defines it as an activity, a conscious, deliberate participation in the process by which resources are allocated among citizens. This conception of politics restricts political activity only in public arena and the private sphere of family life is rendered as apolitical. This publicprivate dichotomy in traditional definition of politics is used to exclude women from public political sphere and even when women are brought into politics they are entered as mothers and wives. Male domination of politics, political parties and culture of formal political structures is another factor that hinders women's political participation. Often male dominated political parties have a male perspective on issues of national importance that disillusions women as their perspective is often ignored and not reflected in the politics of their parties. Also women are usually not elected at the position of power within party structures because of gender biases of male leadership. Meetings of councils or parliamentary sessions are held in odd timings conflicting with women's domestic responsibilities. The larger democratic framework and level of democratization also impact women's political participation. Secular democracies in Europe and also in some of the developing countries have created relatively more space for women's participation in politics as compared to countries where religious orthodoxy has been shaping politics and democracy.

\subsubsection{Economic Factors}

Politics is increasingly becoming commercialized. More and more money is needed to participate in politics. Women lack access to and ownership of productive resource, limiting the scope of their political work.

\subsubsection{Lack of Social Capital and Political Capacities}

Women often lack social capital because they are often not head of communities, tribes or kinship groups, resulting in the absence of constituency base for them and means of political participation such as political skills, economic resources, education, training and access to information (Bari, 2005).

As noted in the Millennium Development Goals, women's equal participation with men in power and decision making is part of their fundamental right to participate in political life, and at the core of gender equality and women's empowerment. Women have to be active participants in determining development agendas. Women who want to enter politics find that the political, public, cultural and social environment is often unfriendly or even hostile to them. Even a quick glance at the current composition of political decision makers in any region provides evidence that women still face numerous obstacles in articulating and shaping their own interests. Current composition of political decision makers in any region provides evidence that women still face numerous obstacles in articulating and shaping their own interests.

\subsubsection{Challenges to the Political Empowerment of Women in Ethiopia}

Current challenges and constraints to the political empowerment of women in Ethiopia are mainly system wide political constraints for empowering women politically. Under these political violence and intensive persecution and increased regimentation of social life which makes independent women civil society organization more difficult are included. Finally, constraints particularly relevant to women includes:

\footnotetext{
\# Absence of strong women's network and movement

* Social ,economic and cultural burdens

\& Limited interest to be involved in politics

* Political discourse which doesn't allow sufficient sphere to the issues of women

* Insufficient attention to political empowerment of women (Bari, 2005).
} 


\subsubsection{Enabling Environment for Women to Participate in Politics and Development in Ethiopia}

In the interconnected world of today, external factors such as globalization, international trade and economic policies impact the development policies of the nation-states. Therefore, the creation of enabling environment for women's participation in politics and in development cannot be viewed only within the boundaries of a country. It must be linked with global factors. Thus, the responsibility to create supportive environment for gender equality and advancement of women as shared responsibility falls equally on the national and international communities. Another important element in the enabling environment relates to the nature of democracy and the level of democratization in society. The participative and decentralized form of governance creates greater space for citizens to participate in governance processes and structures. It also creates space for greater interaction between the state and the society. Human capacities are dependent on the availability of resources such as education, health and employment that build capabilities and enlarge human choices. Access to education, health and employment is directly linked with women's ability to create space for themselves in politics and development. Women's consciousness of their political rights is another critical element for women's individual and collective agency. Political consciousness through building transformative communities is the sustainable way to transform politics and development. A strong women's movement and civil society is another condition of enabling environment that can influence the direction of politics and development in favor of women. Triple roles of women in productive, reproductive and community management spheres must inform the efforts for creating supportive environment for women's political participation

\subsubsection{Successful Strategies for Women's Political Empowerment in Ethiopia}

There are different strategies used to promote women empowerment in politics. Among them gender quotas and women's experience of networking are the most successful strategies. Gender quotas emerged as a global fast tract strategy to redress the historic exclusion of women from the formal arena of politics. Over the last half of the 20th Century, many countries have instituted gender quotas either voluntarily or through legislation. There is a clear consensus in literature that gender quota is an effective tool in addressing women's exclusion and ensuring their presence in formal structure of politics. However, the controversy starts around the vital question as to what extent women's presence in political structures has led to an effective mainstreaming of gender concerns in politics. This has raised issues on the nature and modalities of gender quotas and its limitation to empower women in politics. Gender quotas are instituted within the context of gender disparities, which are structural and systemic. Without addressing the structural constraints to women's political exclusion, their inclusion through gender quota cannot lead to an effective representation. Lastly the wider context of politics and democracy is equally important to determine the success of gender quota for attaining sustainable development. There is also an experiences of collective power through networking where women councilors formed a network. Therefore, women belonging to different political parties decided to create a common forum where women councilors could come together to combat these problems, share their experiences, learn from each other, find ways to become more effective in their newly assigned political roles, resist patriarchal backlash and assert themselves to have their right to access political power. In addition to these strong women's movement and civil society is another condition of promoting women empowerment that can influence the direction of politics and development in favor of women.

\section{Conclusions}

Despite the removal of legal barriers to women's political empowerment, governments remain largely maledominated. Various factors influence women's access to decision-making bodies including: lack of party support, including financial and other resources to fund women's campaigns and boost their political, social and economic credibility, the type of electoral system as well as the type of quota provisions and the degree to which they are enforced, the tailoring of many of these institutions according to male standards and political attitudes, the lack of coordination with and support from women's organizations and other NGOs, women's low selfesteem and self-confidence, endorsed by certain cultural patterns which do not facilitate women's access to political careers and the lack of media attention to women's contributions and potential which also results in the lack of a constituency for women.

There are a range of possible mechanisms to increase women's participation in political life which have had varying degrees of success including: reform of political parties, quotas and other forms of affirmative action, training to develop women's skills and gender sensitivity, work with women's sections of political parties and the development of women's political organizations.

In the interconnected world of today, external factors such as globalization, international trade and economic policies impact on the development policies of the nation-states. Therefore, the creation of enabling environment for women's empowerment in politics and in development cannot be viewed only within the boundaries of a country. It must be linked with global factors. Thus, the responsibility to create supportive environment for women empowerment and advancement of women as shared responsibility falls equally on the national and international communities. 


\section{Recommendation}

Excluding women from positions of power and from elected bodies impoverishes the development of democratic principles in public life and inhibits the economic development of a society. Men, who do not necessarily support women's political empowerment, dominate the majority of governing institutions. Thus it remains imperative to emphasize that women must lead the process to organize and mobilize their networks, learn to communicate their interests with their male counterparts and different organizations, and push for mechanisms to enhance their representation. Therefore, positive action measures should be taken to assure representation that reflects the full diversity of societies, with the target of the 'gender-balanced' legislative body in order to build sustainable development. Based on these premises the following recommendations are made to increase the effort in empowering women in politics for sustainable development in Ethiopia.

* The introduction of political, institutional and financial guarantees that promote women's candidacies to ensure the equal participation of female nominees in electoral campaigns.

* Support and strengthen civil society organizations especially, independent women organizations and programs and initiatives aimed at empowering women in Ethiopia.

* The development and support for schools (centers) for the training of women for participation in electoral campaigns by recognizing that sustainable development goals must include gender equality and political empowerment of women both as a goal in its own right, as well as a fundamental part of all other goals.

* Reform of political parties' quotas and other forms of affirmative action by working with women's sections of political parties and through the development of women's political organizations in Ethiopia.

* Creating an enabling environment which is participative and decentralized form of governance creates greater space for citizens to participate in governance processes and structures. It also creates space for greater interaction between the state and the society.

\section{References}

1) Baden S. \& Oxaal Z (2004). Gender and Empowerment: Definitions, Approaches and Implications for Policy. BRIDGE (development - gender), Report No.40. Brighton, UK

2) Bari F. (2005). Women's Political Participation: Issues and Challenges. Bangkok, Thailand

3) Joshi, ST. (1999). Women and development - The changing scenario. New Delhi: Mittal Publications.

4) Medhin Zewdu, (2002). Sustainable Development in Ethiopia: Report of Assessment of Activities and Issues relevant to the review process of the Earth Summit. Addis Ababa, Ethiopia.

5) United Nations. 2002. Johannesburg Summit 2002. Ethiopia-country Profile. 